\title{
Male residency and dispersal triggers in a seasonal breeder with influential females
}

Christopher Young ${ }^{\mathrm{a}, \mathrm{b}, \mathrm{c}}$, Richard McFarland ${ }^{\mathrm{b}, \mathrm{d}, \mathrm{e}}$, Andre Ganswindt ${ }^{\mathrm{a}}$, Mirjam M.I. Minkner b,f,g , Louise Barrett ${ }^{\mathrm{b}, \mathrm{c}}$, and S. Peter Henzi ${ }^{\mathrm{b}, \mathrm{c}}$

${ }^{a}$ Endocrine Research Laboratory, Mammal Research Institute, Faculty of Natural and Agricultural Science, University of Pretoria, Pretoria, Republic of South Africa, ${ }^{\mathrm{b}}$ Applied Behavioural Ecology and Ecosystems Research Unit, University of South Africa, Florida, Gauteng, South Africa, ${ }^{c}$ Department of Psychology, University of Lethbridge, Lethbridge, Alberta, Canada, ${ }^{\mathrm{d}}$ Department of Anthropology, University of WisconsinMadison, Madison, United States, ${ }^{\mathrm{e}}$ Brain Function Research Group, School of Physiology, University of the Witwatersrand, South Africa, ${ }^{f}$ Behavioural Ecology, University of Leipzig, Germany, ${ }^{g}$ Research Group Primate Kin Selection, Max-PlanckInstitute for Evolutionary Anthropology

Corresponding authors address: Endocrine Research Laboratory, Mammal Research Institute, Faculty of Natural and Agricultural Science, University of Pretoria, Pretoria, Republic of South Africa

Email: Christopher.young@uleth.ca

Word count: 6033 
1 Male residency and dispersal triggers in a seasonal breeder with influential females

2

3

4 Christopher Young ${ }^{\mathrm{a}, \mathrm{b}, \mathrm{c}}$, Richard McFarland ${ }^{\mathrm{b}, \mathrm{d}, \mathrm{e}}$, Andre Ganswindt ${ }^{\mathrm{a}}$, Mirjam M.I. Minkner ${ }^{\text {b,f,g }}$, 5 Louise Barrett ${ }^{\mathrm{b}, \mathrm{c}}$, and S. Peter Henzi ${ }^{\mathrm{b}, \mathrm{c}}$

$6{ }^{a}$ Endocrine Research Laboratory, Mammal Research Institute, Faculty of Natural and 7 Agricultural Science, University of Pretoria, Pretoria, Republic of South Africa, ${ }^{\mathrm{b}}$ Applied 8 Behavioural Ecology and Ecosystems Research Unit, University of South Africa, Florida, 9 Gauteng, South Africa, ${ }^{c}$ Department of Psychology, University of Lethbridge, Lethbridge, 10 Alberta, Canada, ${ }^{\mathrm{d} D e p a r t m e n t}$ of Anthropology, University of Wisconsin-Madison, Madison, 11 United States, ${ }^{\mathrm{e}}$ Brain Function Research Group, School of Physiology, University of the 12 Witwatersrand, South Africa, ${ }^{\mathrm{f}}$ Behavioural Ecology, University of Leipzig, Germany, $13{ }^{\mathrm{g}}$ Research Group Primate Kin Selection, Max-Planck-Institute for Evolutionary 14 Anthropology

17 Corresponding authors address: Endocrine Research Laboratory, Mammal Research Institute, Faculty of Natural and Agricultural Science, University of Pretoria, Pretoria,

19 Republic of South Africa

20 Email: $\underline{\text { Christopher.young@uleth.ca }}$

21 Word count: 6033 
Males in female-philopatric social groupings leave their natal groups in order to pursue successive reproductive opportunities in one or more subsequent groups. In vervet monkeys (Chlorocebus pygerythrus), adult males coexist, and physical eviction is not a driver of male movement. Migratory decisions are expected to turn on an evaluation of future reproductive opportunity, as indexed principally by local operational sex ratio and relative competitive ability. Although vervet males' reproductive success is correlated with dominance, they are distinctive in that the attainment of rank is contingent on integration into female socio-spatial networks and we expect decisions about continued residency to reflect this. We used eight years' data from three groups to confirm that male migration is seasonal in our population, with a peak that is coterminous with androgen levels, and precedes peak mating and conception by four weeks. The average length of completed residency was 459.00 days ( \pm 509.85 SD; Median=400.50), with an increase in the logged rate of departure after 1428 days, which is 150 days longer than the estimated modal age at first conception by putative daughters. There were positive correlations between a male's initial and highest rank, and between his highest rank and the length of time to reach it. We found that a male's residency was positively and independently associated with his highest achieved rank and both his grooming centrality and proximity degree, and that increasing rank and proximity degree also had positive effects on residency length subsequent to the attainment of his highest rank. The probability of emigration was associated negatively with both female number and grooming centrality scores. We conclude that emigration from a group is linked to male rank attainment and mediated by a male's integration into female socio-spatial networks. We found no evidence that emigration preceded the sexual maturity of putative daughters. 
48 Keywords: Male migration; group residency; tenure length; Chlorocebus pygerythrus; social 49 integration; dominance.

50 
Inbreeding avoidance and maximisation of lifetime reproductive success are the two main

54 drivers of dispersal from the natal group and subsequent, secondary migration for males in gregarious mammalian social systems (Greenwood 1980; Pusey \& Packer 1987). At the same time, competition for access to mates is a defining characteristic of mammalian male social life. Where males co-reside in groups (multimale social systems), and other groups are accessible, the duration of a male's tenure in a group is set principally by his local competitive ability (Clarke et al. 2008) and the availability of sexual partners, and circumscribed by the increasing probability of residing alongside reproductively mature female offspring (Henzi \& Lucas 1980; van Noordwijk \& van Schaik, 2004).

Where a male's reproductive opportunities are positively tied to his individual dominance rank - which characterises many primate social organisations (Schülke \& Ostner, 2012) competitive ability is generally assessed in these terms alone. However, in many species, dominance-based reproductive advantages can be circumvented by, for example, coalition formation among males (Bercovitch 1988; Noë \& Sluijter 1995; Young et al. 2013), or the ability of females to choose their sexual partners (see, for example, Dubuc et al. 2011; Young et al. 2013). Vervet monkeys (Chlorocebus pygerythrus) present an interesting intersection of these routes to male reproductive success. While males do form coalitions, these appear to have little impact on mating access (Freeman et al. 2016), and there is a positive correlation between rank and both mating opportunities (Freeman et al. 2016) and paternity (Minkner et al. 2018). At the same time, however, we have shown that, in addition to any agonistic efforts on his own behalf, improvement in a male's rank-and therefore in his reproductive opportunities - is tied to the extent to which he is socially and spatially integrated in the 
76 female network, indicating an additional, indirect role for the expression of female choice

77 (Young et al. 2017a). The fact that vervet males rise in rank relatively slowly during their expect further rank improvement, even if this does not materialise. dispersal in this species.

tenure (see below) also points to a need to cultivate females to this end and suggests that relevant social factors will therefore also factor into decisions about tenure and the timing of

We take advantage of a data set spanning eight years and three large social groups to consider the factors that influence group residency length in male vervet monkeys, and the factors that may trigger a male's decision to leave their current group. Vervet females are philopatric and males leave their natal groups to commence their reproductive careers in other groups, from which they will subsequently also emigrate, with no time spent as a solitary animal (Henzi \& Lucas 1980). After confirming that male migration maps onto the mating season at our site so demonstrating that the decision to leave a group is concordant with the pursuit of reproductive interests - we first assess the extent to which the duration of a male's residence in any one group is tied to the attainment of rank. While the achievement of a particular rank rests, in part, on a male's intrinsic physical condition, females also have an important and persistent role to play (Young et al. 2017a). We predict, therefore, that the extent of rank improvement will be positively correlated with residency length, as males construct and develop important relationships with females. If this is so, we also predict positive correlations between the highest rank achieved, the extent of socio-spatial integration, and the length of residency after the achievement of this rank. Clearly, a male who is high ranking would be expected to capitalise on this, while one that is socially integrated might justifiably 
100 We then examine the possible factors that trigger a male's decision to leave a group. In

101 addition to a male's mating success in the previous mating season and unfavourable shifts in

102 the operational sex ratio (more males, fewer reproductively active females), we expect

103 declines in both rank and socio-spatial integration to increase the likelihood of departure to

104 another group. In this vein, we also use a much larger data set, a more accurate estimate of

105 female sexual maturity (3.5 years or 1278 days), and a more appropriate analytical approach,

106 to revisit an earlier proposition that vervet male residency has an upper limit that is set by the

107 modal age at which putative daughters begin reproducing, and is thus geared to lower the risk

108 of inbreeding (Henzi \& Lucas 1980).

\section{METHODS}

\section{Study site and subjects}

114 At the Samara Private Game Reserve, South Africa ( $\left.32^{\circ} 22^{\prime} \mathrm{S}, 24^{\circ} 52^{\prime} \mathrm{E}\right)$, we collected data

115 between September 2009 and December 2016 on three groups (PT, RBM, RST) of wild, fully habituated and individually recognisable vervet monkeys, occupying semi-arid riverine

117 woodland (Pasternak et al. 2013). Group composition varied across the three groups and the study period ( $\mathrm{N}_{\mathrm{RBM}}$ Males: 4-19, $\mathrm{N}_{\mathrm{RBM} \text { Females: }}$ : $1-17$; $\mathrm{N}_{\mathrm{RST}}$ Males: 5-19, $\mathrm{N}_{\mathrm{RST}}$ Females: 11-22; $\mathrm{N}_{\mathrm{PT}}$ Males: 3-12, N $\mathrm{N}_{\text {PT Females: }}$ 8-11). Each group was followed for 10 hours per day. Due to variation in the length of daylight hours across the year, we balanced our daily follows in summer so that there were equal numbers of days that began at dawn and finished 10 hours later and days that began later and ended at dusk. In winter, daylight hours (07:30-17.30) generally coincided with our sampling period. 


\section{Behavioural data collection}

We used scan sampling (Altmann 1974) at 30-minute intervals to record the general activity (resting, moving, foraging or allo-grooming) of each adult group member and the identities of all its neighbours within a $2 \mathrm{~m}$ radius, across each study day $(\mathrm{N}=493,756$ scans) (McFarland et al. 2015; Pasternak et al. 2013). Each scanning period lasted a maximum of 10 minutes in order to ensure as many animals as possible were sampled (i.e., to permit researchers to identify animals beyond the researchers' immediate vicinity), and most individuals were recorded in each scan. Additionally, for records of allo-grooming, we recorded both the identity of the partner and the direction of grooming. Agonistic behaviours were recorded ad libitum.

\section{Dominance rankings and power trajectories}

Our study was divided into 3-month blocks fixed by the mating (April-June) and birth seasons (October-December), separated by the January-March and July-September periods. Data from on-going, ad libitum observations of decided dyadic agonism $(\mathrm{N}=5,212)$ were then used to construct male-male dominance hierarchies for all adult males in each threemonth period. For each group, in each time period, dominance rank was expressed as a standardized normalized David's score (SDS), using the excel macro from the package "DomiCalc" (Schmid \& de Vries 2013). We standardized our dominance ranks in order to permit comparisons across groups and time. To do so, we divided each individual's Normalised David's score by the highest score for that period/group, such that the highest ranked individual had a score of one (Henzi et al. 2013). Using decided dyadic agonism, we determined the level of aggression each male received from females over each 3-month block. As our study site is situated in open, semi-arid riverine woodland with high levels of visibility of all group members, we are confident we missed very few agonistic interactions 
within our groups. We also controlled for observer effort (number of observers per group per scan day; range 1-3) and for the presence of each individual animal in the group on each scan day (based on daily group census of an individual animal's presence/absence within the group).

We estimated each male's power trajectory by determining Elo-ratings (Albers \& de Vries 2001; Neumann et al. 2011), using the R package "EloRating" (Neumann et al. 2011) and the function "traj.elo". For a full description of the method see Young et al. ( 2017a). In brief, a male's Elo scores at the start and end of each three-month period were used to describe his power trajectory, expressed as the slope of the line connecting them. Positive and negative slopes indicate increasing and decreasing power within the group respectively, while the magnitude of the slope identifies the rate of increase or decrease. In order to provide a stable baseline for the Elo ratings we used the 3-month period prior to the beginning of analyses, i.e., between September and December 2009 to generate each males' initial rating. The number of points that can be won or lost is determined by the kalue, which we set to the recommended moderate level of 100 (Neumann et al. 2011).

Social indices

We described social relationships, using our scan data, to construct spatial $(<2 \mathrm{~m})$ and grooming association matrices for each three-month block. In doing so, we controlled for both the number of weeks each male was in each group and for observation effort by dividing each dyadic association score by the total number of scans in which each dyad member was observed. We looked at a male's total level of social integration by examining social

173 relationships between all adult group members. We derived two measures of association from 174 the social network (SN), which have been shown to be important social measures in our 
175 population previously (Josephs et al. 2016; McFarland et al. 2015; Young et al. 2017b). We 176 used Eigenvector Centrality (EC), which estimates a male's centrality as a function of his

177 partners' centrality, to estimate the extent of male integration, while degree was used to 178 account for the number of females to which a male was connected and strength to estimate 179 the magnitude of a male's social ties. We considered grooming and proximity association 180 separately, as each targets different network properties (Castles et al. 2014). Our previous research found that, for males, the two most important social measures were grooming EC and proximity degree and thus these measures were included in the present analysis.

Mating and conception

185 We used observed mating as our index of reproductive access (Freeman et al. 2016; Minkner et al. 2018). We recorded all observed copulations between males and females on our three groups ad libitum. Our field site is an open habitat and therefore, given multiple observers, we are confident that we were able to record most copulations without spatial bias. For each mating season we determined the number of copulations for each male. We divided this score by the total number of copulations for that group and year to give the proportion of all copulations each male received each year. Female conception date was calculated from the date of birth of an infant using a gestation estimate of 165 days.

194 Residency length

195 We determined group residency length for each individual male as the total time in days that a male was scored as present in a group and was recorded in scan samples. 
199 Faecal samples for steroid analyses were collected from all adult males on a bi-monthly basis

200 as part of a long-term project investigating vervet monkey physiological stress. In order to

201 identify seasonal alteration in androgen production we selected five males, analysing one

202 sample from each over the period Jan - May 2016. This gave a total of five samples per male.

203 The faecal sample collection and processing used standardized protocols for both the field and the laboratory and are described in Young et al. ( 2017b). Steroid extraction as well as enzyme immunoassays (EIA) were conducted at the Endocrine Research Laboratory, University of Pretoria. We examined androgen production via quantification of immunoreactive faecal androgen metabolites (fAM) using a T-3-CMO EIA. Details of the EIA, including cross-reactivities of the antibody used, are described by Palme \& Möstl (1993) and all steroid concentrations are given as ng/g faecal dry weight (DW). The EIA was performed using a standardized protocol (see Ganswindt et al. 2002) and biologically validated for the species by contrasting fAM concentrations of sexually mature $(n=5$; median fAM: 623 ng/g DW) and immature $(\mathrm{n}=9$; median fAM: 209 ng/g DW) males $(\mathrm{T}=$ $57 ; \mathrm{P}=0.011$ ). The sensitivity of the EIA used was $2.4 \mathrm{ng} / \mathrm{g}$ faecal DW. Intra- and Interassay coefficients of variation, of high- and low- value quality controls, were $4.7 \%$ and $6.2 \%$ as well as $8.8 \%$ and $12.7 \%$, respectively.

\section{Statistical analysis}

218 With one exception, all statistical analyses were run in R 3.2.2. (R-Core-Team, 2016).

219 We used a Rao spacing test to examine if the observed number of migrations per month varied from that of uniform distribution using the r package "circular" (Agostinelli \& Lund 2011). To describe the relationship between the timing of male migration, mating and conceptions, we used the "forecast" package in R (Hyndman \& Khandakar 2008) to identify

223 the lag in weeks at which the respective cross-correlations were highest. 
225 Using data only from non-natal males, we first determined whether the probability of male

226

227

241 We ran a second survival analysis using a cox proportional hazards model in order to departure was independent of the duration of his residency (i.e., whether the "failure" rate was constant), by fitting the data to an exponential distribution in JMP 13 (2013). Following visual examination of the fit, we used the 'survival' platform in JMP to derive estimates of survival that accounted for censored data. We then used the "segmented" package in R (Vito 2008) to establish whether the regression between log survival and residency length was the best fit by separate line segments. Breakpoints were evaluated by checking the corresponding gap coefficient and its $t$-value, (breakpoint accepted when $t<2.0$ ).

We ran a time-dependent cox proportional hazards model (Mills, 2011; Therneau \& Grambsch, 2013), using the "coxme" package (Therneau \& Therneau 2015) to examine the influence of social network position and SDS on male residency length (model 1). We included residency length in days as our time series along with three predictor variables: 1) a male's highest rank position, 2) his highest grooming EC score and, 3) his highest proximity degree score.

investigate if male residency length subsequent to achieving their top rank position was predicted by their social network position and their highest rank position (model 2). We specified group residency length subsequent to achieving top rank as the response variable and included the following predictor variables: 1) highest SDS; 2) highest grooming EC score; 3) highest proximity degree score and, 4) residency length prior to achieving their highest rank as a statistical control. 
249 We then ran a third cox regression model (model 3) with time-varying covariates (Mills, 250 2011; Therneau \& Grambsch, 2013) to examine the influence of the predicted time-varying

251 factors on a male's decision to leave. We split each male's tenure into three-month blocks 252 with the male's status at the end of each three-month block being stay or migrate (binary: 0/1) 253 from the group, this gave 37 known migratory events, and 386 three-month blocks from 56 254 males (19 males with censored data; seven migratory events and 12 censored males could not 255 be included in this analysis as these males stayed for three months or less and differences in 256 social metrics between two periods could not be calculated). This allowed us to test a number 257 of time-varying and binary covariates using the function "coxme" to allow for random 258 effects. If a male migrated after one month or less in a time block, we used the previous time 259 period as his last time block to determine our dependent variables, as periods of less than one 260 month are too short for data to be reliable. All numeric predictor variables were standardized to provide a mean of 0 and standard deviation (SD) of 1 . Our predictor variables were: 1 ) the difference in value of a male's SN measures from the beginning to the end of a three-month block for proximity degree and grooming EC, 2) the difference in SDS from the beginning to the end of a three-month block, 3) a male's power trajectory, 4) a male's mating success during the previous mating season, 5) the proportion of female group members with dependent infants and, 6) the number of adult females in the group.

268 We incorporated right-censored data in all the cox regressions to account for animals that had 269 not yet left the group at the end of the study period, and we included only individuals who were observed to have emigrated to one of the study groups or three semi-habituated neighbouring groups (i.e. not individuals that might have died rather than migrated). For all 272 models we included individual identity nested within group as a random effect as well as 273 random slopes for the grooming EC variable in model 3. 
275 In order to check the validity of our cox models we examined the Cox-Snell residuals, scaled

276 Schoenfeld residuals using the function "cox.zph" in the R package "survival" (Therneau 277 2014) and, for influential cases, used df beta to look at score residuals (Mills, 2011; Therneau 278 \& Grambsch, 2013). Using the function "vif” from R package “car" (Fox \& Weisberg, 2011), 279 we examined variance inflation factors (VIFs) derived from linear (models 1 and 2) and 280 binomial (model 3) models containing all predictor variables to assess collinearity. All VIFs 281 were $<2$, indicating that collinearity was not an issue (Pan \& Jackson 2008). We used the 282 'MuMIn' package (Barton \& Barton 2015) to generate marginal and conditional $\mathrm{R}^{2}$ values for 283 the whole models using the function "r.squaredLR" (Nakagawa \& Schielzeth 2012).

284 To examine if there was a difference in the length of time it took a primary or secondary 285 migrator to achieve their top rank, and to deal with small sample sizes, we ran a Bayesian two 286 sample t-test, using the "bayes.t.test" function from the "Bolstad" package (Curran \& Bolstad 287 2017) to address the small sample size.

288 We follow Colquhoun (2014) in describing outcomes as indicating weak ( $P \sim 0.05)$, moderate $289 \quad(\mathrm{P} \sim 0.01)$ or strong $(\mathrm{P} \sim 0.001)$ evidence for effects.

290 Ethical note: All protocols were non-invasive and adhered to the laws and guidelines of South 291 Africa and Canada. Procedures were approved by the University of Lethbridge Animal 292 Welfare Committee (Protocols 0702 and 1505). This study also adheres to the ASAB/ABS 293 Guidelines for the Use of Animals in Research.

\section{RESULTS}


298 Over the course of the entire study period, 138 males were observed to reside in our study 299 groups. Of these males, 14 are known to have died, 20 males were present at the start of the 300 study (of which 12 had known subsequent emigrations) and 19 males were present at the end 301 of the study period. Of the remaining 90 males, 63 migrated to a new adjacent group, of

302 which 19 were by males leaving their natal groups. Including immigrants of unknown 303 provenance did not affect the outcomes. All known males transferred directly into adjacent 304 groups. Males migrated most frequently in the months of April and May (45 of 63 migrations) and the distribution of migration was not uniform (Rao spacing statistic $=$ 297.692, $\mathrm{N}=63, \mathrm{P}<0.001)$. We also found six incidents of parallel migration, where two

307 males from the same group moved on the same day. We had one observation of a 3-year-old 308 juvenile migrating with a 4-year-old and a 5-year-old sub-adult between two of our study 309 groups.

311 There was a correlation between the number of migrations that occurred in a given week of

312 the year and the number of female conceptions in the same week $\left(\mathrm{r}=0.54, \mathrm{~N}_{\text {weeks }}=52\right.$;

$\left.313 \mathrm{~N}_{\text {conceptions }}=180 ; \mathrm{N}_{\text {migrations }}=63, \mathrm{p}<0.001\right)$. A similar outcome was found for the number of matings in a given week and the number of male migrations in that week $\left(\mathrm{r}=0.57, \mathrm{~N}_{\text {matings }}=\right.$ $353, \mathrm{p}<0.001)$. However, the fit between migrations and both number of female conceptions and matings was improved if matings and conceptions were lagged by 4 weeks (Conceptions:

$317 \mathrm{r}=0.810, \mathrm{~N}_{\text {weeks }}=52, \mathrm{~N}_{\text {conceptions }}=180, \mathrm{P}<0.001 ;$ matings: $\mathrm{r}=0.81, \mathrm{~N}_{\text {weeks }}=52, \mathrm{~N}_{\text {matings }}=$ $318353, \mathrm{p}<0.001)$

320 The level of fAM rose from January until April, when they peaked alongside migrations 321 (Figure 1). 
324 Figure 1: Showing kernel density estimates of the number of male migration events (yellow),

325 the number of copulations (dark blue) and the number of conceptions (sky blue) per week of

326 the year (1-52 weeks). Also shown are the mean \pm SD fAM levels of five males for the

327 months of January to May in order to show the timing of peak androgen production.

328

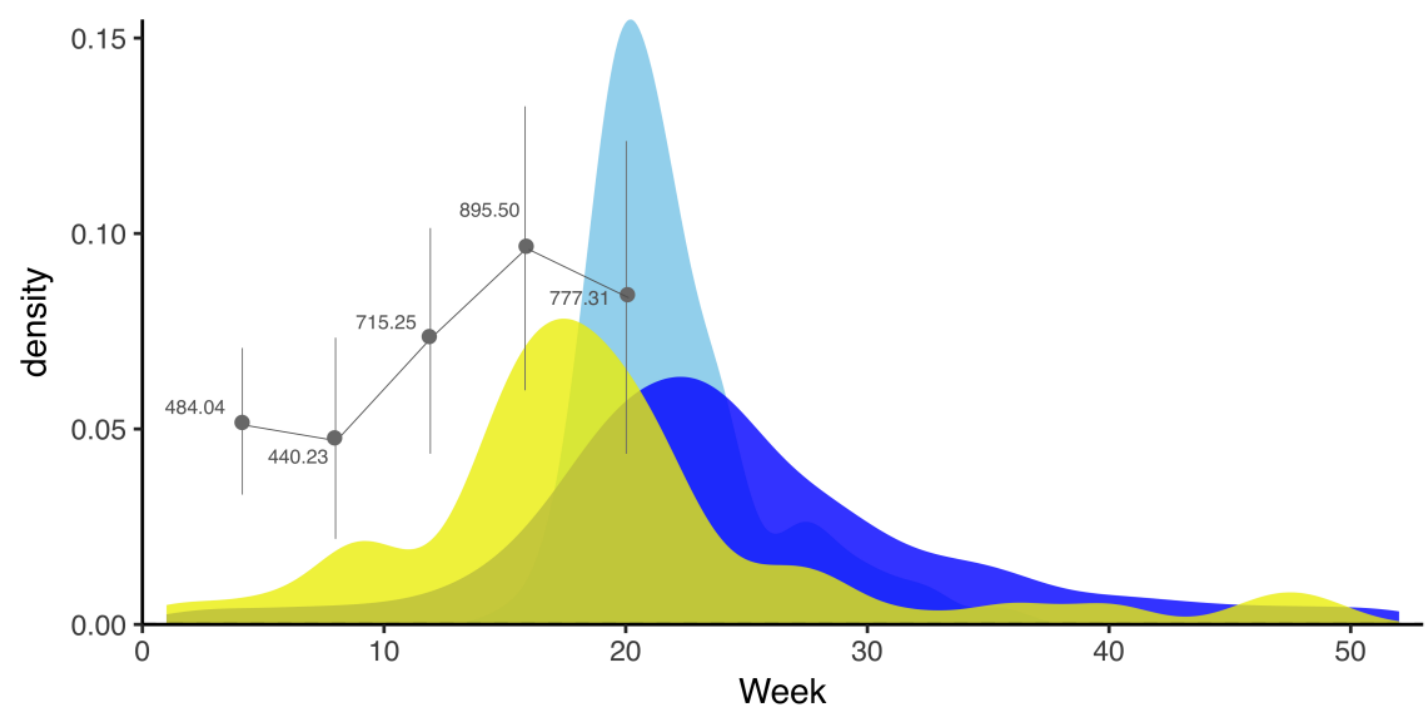

329

330

331

What predicts group residency length?

332 The completed residency length for 44 non-natal males was 459.00 days $( \pm 509.85$ SD.

333 Range 31 - 2696 days; Median: 400.50). The duration of non-natal male residency was best

334 described by an exponential distribution (Kolmogarov's D: 0.071; N= 44 migratory events

335 plus 32 censored males; $\mathrm{P}=0.15)$, indicating that the overall probability of departure was

336 independent of the duration of residency. Nevertheless, visual examination revealed

337 directional deviations from the fit to the regression at long durations, suggesting the emergence of other processes. This was confirmed by segmented regression, which estimated two breakpoints: one at 1428.13 days $(\beta=-3.36 \mathrm{e}-04 \pm 7.62 \mathrm{e}-06 \mathrm{SE}, \mathrm{t}=-44.06)$, after which

340 the slope was steeper $(\beta=-4.59 \mathrm{e}-03 \pm 2.67 \mathrm{e}-04 \mathrm{SE}, \mathrm{t}=-17.23)$, indicating an accelerating 
341 probability of departure, and one at 1529.17 days, after which it was essentially flat $(\beta=-$

$3422.93 \mathrm{e} 05 \pm 3.07 \mathrm{e}-05 \mathrm{SE}, \mathrm{t}=-0.96)$ and accounted for simply for the persistence of three males

343 (Figure 2). Given this, we restricted comparison to the first two slopes, and used the "pscore 344 test" function (Vito 2008) to confirm that they differed (Pscore $=-2.877, \mathrm{P}<0.001$ ).

$346<$ Insert figure 2 here $>$

347

348 Figure 2: The log-survivorship curve of non-natal males as a function of residency length (red

349 circles). The best-fit segmented regression slopes are fitted as a solid black line $\left(\mathrm{R}^{2}{ }_{\text {adj. }}=\right.$

350 0.99), and the two identified break points are indicated by dashed lines. The modal age at first

351 birth by females is indicated by the dotted line.

352

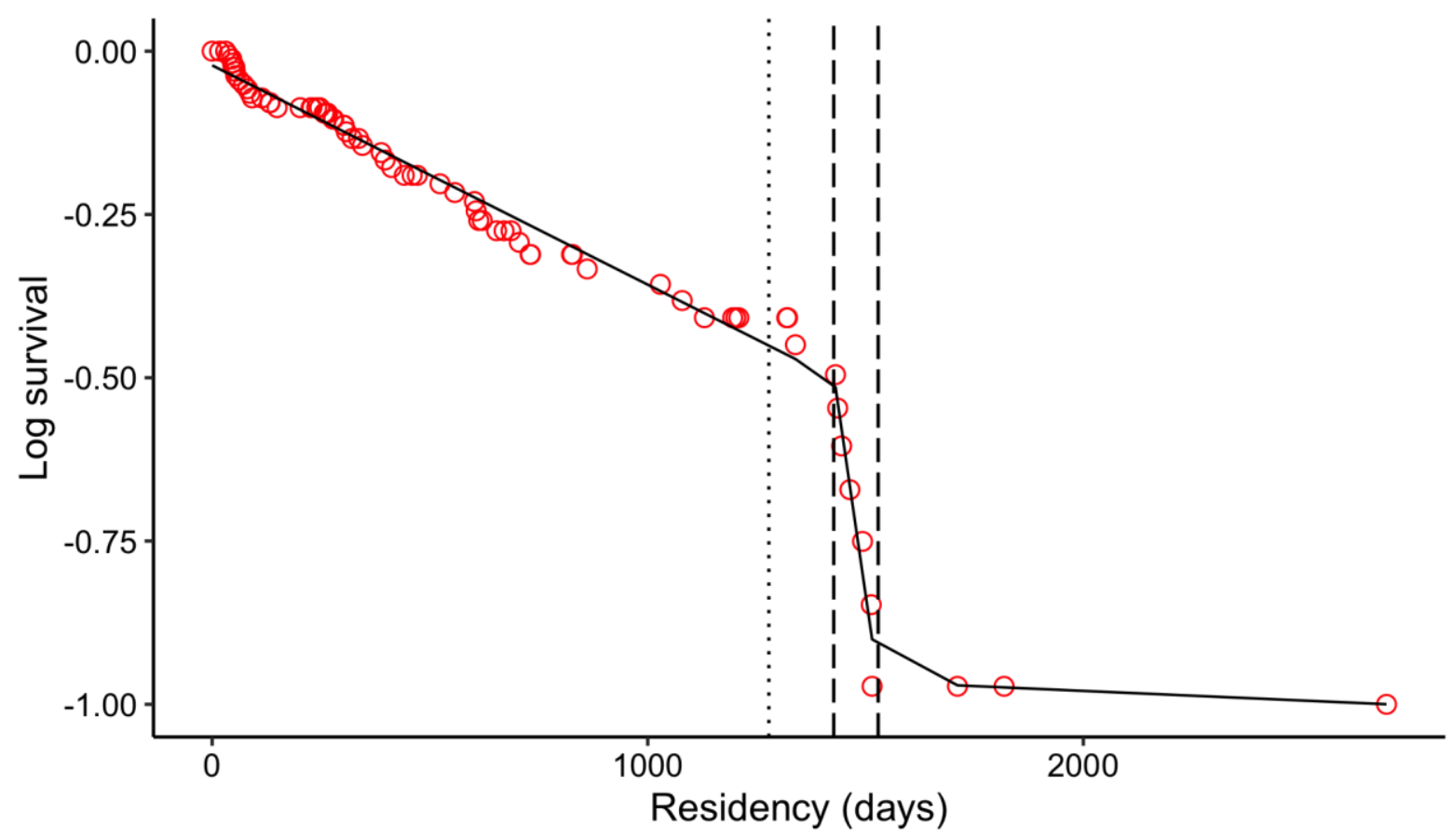


355 There was moderate evidence of a correlation between a male's initial rank on entering a 356 group and the highest rank he achieved in that group (Pearson's $r=0.39, \mathrm{~N}=42, \mathrm{P}=0.010$ ).

357 At the same time, there was strong evidence that the number of days it took a male to reach 358 his highest rank $(484.00 \pm 403.922$, Median $=364$ days $)$ was positively correlated with the 359 rank itself (Pearson's $\mathrm{r}=0.645, \mathrm{~N}=42, \mathrm{P}<0.001$ ). In this regard, there was a meaningful 360 difference between the time it took for primary $(500.13 \pm 384.44$ days, Median $=356$ days $)$ or secondary migrators $(261.67 \pm 166.41$ days, Median $=242$ days $)$ to reach their top rank after immigration (Bayes t-test: $\mathrm{t}=3.24$, $\mathrm{df}=16, \mathrm{P}=0.005, \mathrm{CI}=134.91-646.48$ days, $\mathrm{N}_{\text {Primary }}=8, \mathrm{~N}_{\text {Secondary }}=9$ ).

We ran a survival analysis (model $1, \mathrm{~N}=44$ migratory events plus 32 censored males) to investigate if male residency length was predicted by rank, grooming EC and proximity degree. The results indicate that our predictor variables had a clear influence on residency and differed from the null model (LR test: $\left.\mathrm{X}^{2}{ }_{3}=60.3, \mathrm{P}<0.001\right)$. Increases in the rank and proximity variables had strong negative effects on the probability of emigration whilst grooming EC showed a negative statistical trend (Table 1). As the highest rank a male achieved increased by one unit, the likelihood of emigration decreased by $67 \%$ (hazard ratio

$372=0.325)$. Similarly, for proximity degree an increase of 1 unit decreased the likelihood of 373 departure by $56 \%$ (hazard ratio $=0.437$ ) and a increase in grooming EC of 1 unit decreased 374 the likelihood of departure by $37 \%$ (hazard ratio $=0.625)$.

$<$ Insert table 1 here $>$

378 Table 1: Output of the cox proportional hazards model to investigate the influence of three 379 social factors on a male's group tenure length (Model 1). Social factors were 1) the highest 
rank position a male achieved, 2) the highest grooming EC score a male achieved and 3) the highest proximity degree score a male achieved. $\mathrm{N}=44$ migratory events plus 32 censored males. Whole model: $\log$-likelihood $=-149.71: \mathrm{X}^{2}{ }_{3}=60.30, \mathrm{P}<0.001 ; \mathrm{R}^{2}$ adj $=0.570 . \beta$ is the hazard rate coefficient where a positive value indicates an increased risk of a male migrating.

\begin{tabular}{|l|l|l|l|c|}
\hline Factor & B \pm se & $\begin{array}{l}\text { Hazard } \\
\text { ratio }\end{array}$ & z value & $\operatorname{Pr}(>|\mathbf{z}|)$ \\
\hline $\begin{array}{l}\text { Highest rank a } \\
\text { male achieved }\end{array}$ & $-1.124 \pm 0.293$ & 0.325 & -3.830 & $<0.001$ \\
\hline $\begin{array}{l}\text { Highest grooming } \\
\begin{array}{l}\text { EC a male } \\
\text { achieved }\end{array}\end{array}$ & $-0.469 \pm 0.272$ & 0.625 & -1.730 & 0.084 \\
\hline $\begin{array}{l}\text { Highest proximity } \\
\text { degree a male } \\
\text { achieved }\end{array}$ & $-0.827 \pm 0.250$ & 0.437 & -3.300 & $<0.001$ \\
\hline
\end{tabular}

387

We found moderate evidence that the length of a male's tenure subsequent to the achievement of his highest rank was predicted by the highest rank position that he had achieved (model 2, $\mathrm{N}=44$ migratory events plus 19 censored males). With each decrease in rank by one unit, the probability of staying for longer in the group decreased by $63 \%$ (hazard ratio $=0.37$ table 2 ; Figure 3 ). We also found a moderate effect for proximity degree, where a one-unit reduction in degree led to a $69 \%$ decrease in the probability of staying longer

394 (hazard ratio $=0.31$, table 2). In the aggregate, our predictor variables had a clear influence 395 on residency after achieving top rank and differed from the null model: LR test: $\mathrm{X}^{2}{ }_{4}=24.58$, $396 \mathrm{P}<0.001)$. 
400 Table 2: Output of the cox proportional hazards model (Model 2) to investigate the influence 401 of social factors on a male's group tenure length subsequent to achieving his highest rank.

402 Social factors were 1) the highest rank position a male achieved, 2) the highest grooming EC 403 score a male achieved, 3) the highest proximity degree score a male achieved and 4) a male's 404 group residency length before achieving their highest rank. $\mathrm{N}=44$ migratory events plus 19 405 censored males. Whole model: $\log$-likelihood $=-140.23: \mathrm{X}_{4}{ }_{4}=24.58, \mathrm{P}<0.001 ; \mathrm{R}^{2}{ }_{\text {adj }}=0.341$. $406 \beta$ is the hazard rate coefficient where a positive value indicates an increased probability of 407 longer tenure length.

\begin{tabular}{|l|c|c|c|c|}
\hline Factor & $\mathbf{\beta} \pm \mathbf{s e}$ & $\begin{array}{l}\text { Hazard } \\
\text { ratio }\end{array}$ & $\mathbf{z}$ value & $\operatorname{Pr}(>|\mathbf{z}|)$ \\
\hline Highest rank achieved & $-0.994 \pm 0.410$ & 0.370 & -2.450 & 0.014 \\
\hline $\begin{array}{l}\text { Highest grooming EC } \\
\text { achieved }\end{array}$ & $-0.283 \pm 0.400$ & 0.753 & -0.710 & 0.480 \\
\hline $\begin{array}{l}\text { Highest proximity } \\
\text { degree achieved }\end{array}$ & $-1.184 \pm 0.459$ & 0.306 & -2.580 & 0.010 \\
\hline $\begin{array}{l}\text { Group residency length } \\
\text { prior to highest rank }\end{array}$ & $0.574 \pm 0.389$ & 1.775 & 1.480 & 0.140 \\
\hline
\end{tabular}

$<$ Insert figure 3 here $>$

412

413 Figure 3: The relationship between rank and male residency length (model 2). The y-axis 414 indicates survival probability, while the x-axis indicates the number of days in residence. For 415 illustrative purposes the data are split into two groups: males of high rank (solid black line) 416 versus males of low rank (dashed red line). 


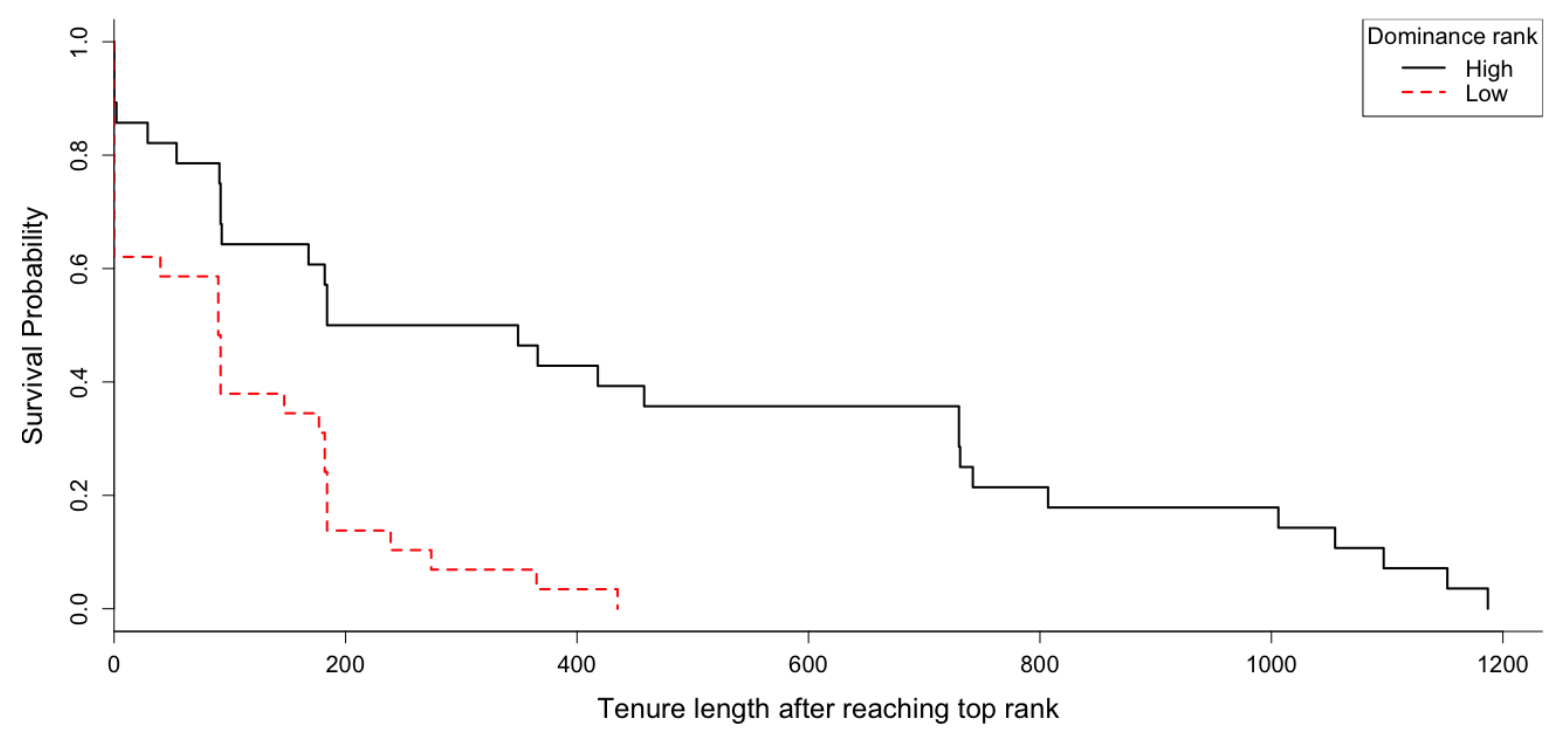

418

419

420

421

422

423

424

425

426

427

428

429 probability of emigration.

433

434

$<$ Insert table 3 here $>$

\section{What factors trigger male migratory decisions?}

We ran a survival analysis to investigate if social factors influenced a male's decision to leave his current group. Overall, the model (model 3, $\mathrm{N}=37$ migratory events plus 19 censored males) showed that changes in our predictor variables influenced the probability of emigration (Table 3. Log-likelihood ratio test comparing the full model to the null model with no predictor variables: $\left.\mathrm{X}_{8}^{2}=15.75, \mathrm{P}=0.046\right)$. The model outcomes indicate that the number of females in the group had a weak influence on a male's probability of emigrating, with each increase in female group membership equating to a $41 \%$ reduction in the probability that a male would leave (hazard ratio $=0.59$ ). We found, too, a negative effect of grooming EC difference on the likelihood of emigration. As grooming EC score increased by one unit the probability of emigration dropped by $36 \%$ (hazard ratio $=0.64$. Table 3 , Figure 4). There was little evidence that changes in the other predictor variables influenced a male's 
436 Table 3: Output of the cox proportional hazards model to investigate the influence of several

437 social factors on a male's decision to emigrate or not $(\mathrm{N}=37$ migratory events plus 19

438 censored males). Social factors were the number of males and females, male standardised

439 rank, male power trajectory, two SN measures (grooming EC and proximity degree), the

440 proportion of female with a dependant infant, and male mating success. Whole model: log-

441 likelihood $=-97.617: \mathrm{X}_{8}^{2}=15.75, \mathrm{P}=0.046, \mathrm{R}_{\text {adj }}^{2}=0.07 . \beta$ is the hazard rate coefficient

442 where a positive value indicates an increased risk of a male migrating.

443

444

445

446

447

448 Figure 4: The influence of increasing or decreasing social integration (grooming EC) on the

449 decision to leave a group (model 3). The y-axis indicates the probability of survival, while the

450 survival time in three-month time blocks from entry into the group (time 0 ) is indicated on

451 the x-axis. For illustrative purposes the data are split into two groups: increase in grooming

452 EC (solid black line) and decrease in grooming EC (dashed red line). 


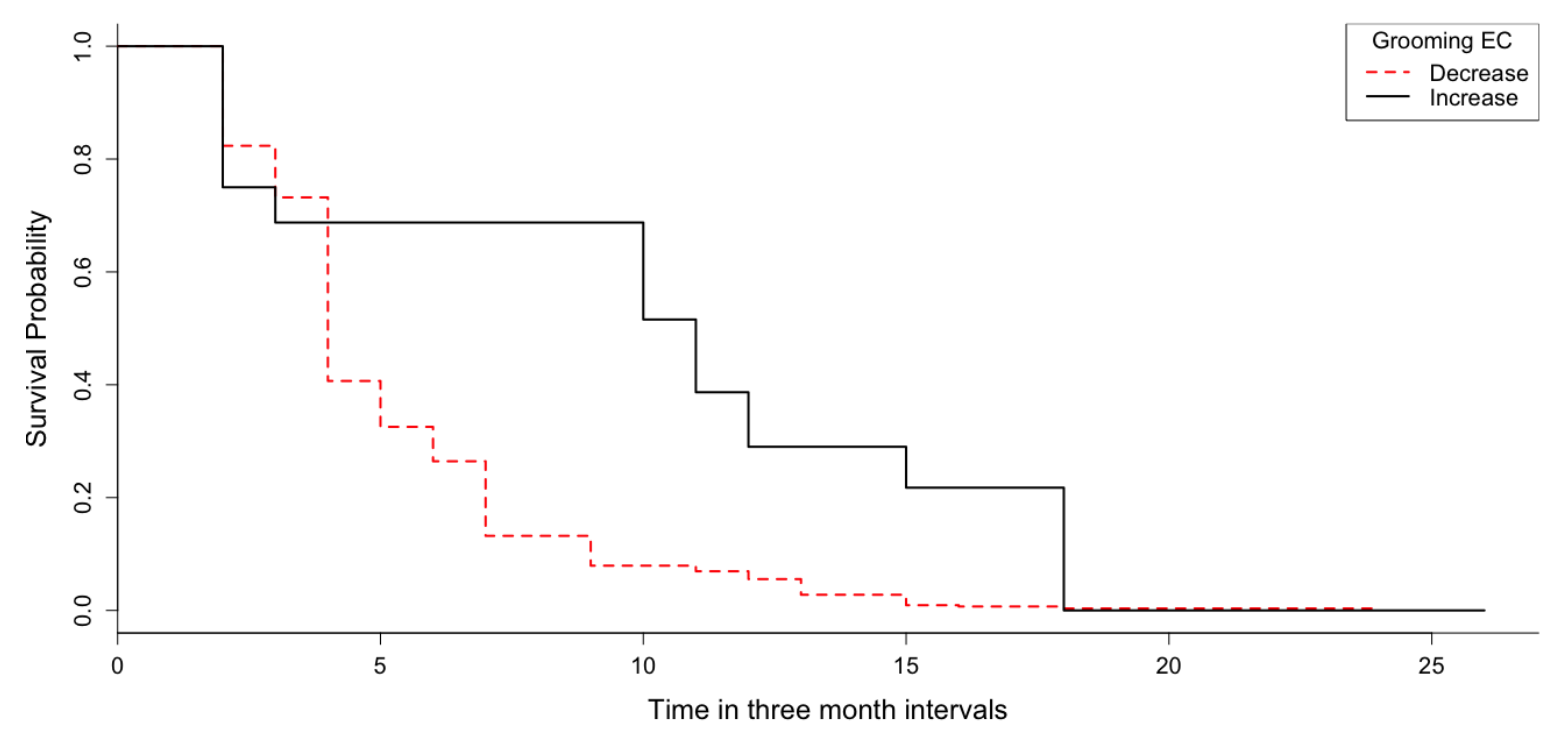

454

455

456

457

458

459

460

461

462

463

464

465

466

467

468 While immediate access to mating opportunities is undoubtedly important, it is also clear that 469

470

471

\section{DISCUSSION}

Not unexpectedly, our results confirm that the probability of movement between groups by male vervet monkeys in our study population is seasonally structured, as it is in a subtropical area in South Africa (Henzi \& Lucas 1980). Male migratory movement is strongly positively correlated with female reproductive activity (see also Cheney \& Seyfarth 1983), with a peak that precedes the corresponding peaks in mating activity and conception by approximately four weeks. In the absence of an extra-group phase, the close alignment of the rise in migration with a rise in testicular androgen, suggests that the latter is the proximate physiological trigger that places most males in their new groups in time to take advantage of the rise in conceptive mating opportunities, especially when it may take a month for them to move from the periphery to the centre of the group (Cheney \& Seyfarth, 1992).

the real benefits of residency are tied to tenure length. Unlike chacma baboons (Papio hamadryas ursinus), for example, where male rank is fundamentally tied to physical condition and achieved very soon after arrival in to a group (Henzi et al. 2010), vervet males 
472

473

474

475

476

477

478

479

480

481

482

483

484

485

486

487

488

489

490

491

492

493

494

495

496

\section{3}

need time to rise in rank. Although initial rank is positively correlated with highest achieved rank, suggesting a role for physical condition, it also takes longer to rise to high rank, indicating the importance of social factors, as does the fact that secondary non-natal migrators rise in rank more rapidly than primary non-natal migrating males, which hints that secondary migrators may be more socially adept. With rank underpinning reproductive success, and a median time needed to reach maximum rank of 364 days, it is not surprising that, on average, a male stays in a group long enough to participate in the subsequent mating season (400 days), or that males achieving higher ranks capitalise on this by extending their stay for longer after doing so.

What is more surprising is that a decline in rank is not a factor in a male's decision to curtail his residency, which is presaged instead by a decline in the number of females and his grooming network integration. As measures of social and spatial integration are independent predictors of residency length, it may well be that, in addition to their roles in male rank acquisition (Young et al. 2017a), they also have direct consequences for a male's reproductive opportunities. Vervet females are co-dominant to males, a finding we have argued is tied to their ability to regulate male mating access (Young et al. 2017a). It may be that social integration undercuts or overrides the consequences of rank loss, which is principally likely to be experienced as a declining capacity to prevent other males from mating, and which can be countered by the direct expression of female choice. If so, declining social connectedness would be expected to be a powerful trigger of departure.

94 The obvious problem with this argument is that our data are correlational: we do not know whether males leave because their network is disintegrating or whether their network centrality declines because an increasing probability of departure makes them disinclined to 
sustain relationships. As our data indicated, female availability appears to be a powerful enough trigger on its own. To resolve this issue, we need information on the dynamics of male-female interactions over time, so that we can generate a better understanding of who is

500 responsible for the maintenance of relationships over time. We have been collecting relevant

501 data to address this issue and will report on it elsewhere.

502

503 Finally, our data allow us to comment on the proposition that vervet male residency is 504 ultimately constrained by the reproductive maturity of putative daughters (Henzi \& Lucas 505 1980). While we show that there is strong evidence for a downturn in the probability of 506 residency after 1428 days, this occurs 150 days ( $\sim 5$ months) after the modal age of 507 conception for primiparous females in our population. Consequently, if daughters are setting 508 an upper limit to residency, this is not underpinned by selection for some anticipatory proximate mechanism that results in males emigrating before their daughters are sexually mature, as argued by Henzi \& Lucas (1980). Indeed, as shown for capuchins (Cebus

511 capucinus) by Muniz et al. (2006), there is no need for a male to leave in order to avoid 512 inbreeding, since a proximate mechanism such as phenotype matching (Alberts 1999), or an aversion to mating with females who were socially associated as non-adults (Westermarck,

514 1891), will produce the same outcome without incurring the costs of migration. Rather, 515 given the importance of female number as a trigger of movement, our results suggest that the 516 sexual maturity of daughters should be seen as exacerbating the perceived decline in 517 available sexual partners.

518

ACKNOWLEDGEMENTS

520 We are grateful to Mark and Sarah Tompkins for permission to work at Samara Private Game

521 Reserve. We are indebted to all students and research assistants that assisted with data 
522 collection, and to Kitty and Richard Viljoen for logistical support. We thank Stefanie 523 Ganswindt and the Endocrine Research Laboratory for endocrine extraction and 524 measurements. This research was funded by National Research Foundation (South Africa) 525 awards to SPH, Natural Science and Engineering Research Council (Canada) awards to SPH 526 and LB, the CRC research program to LB. CY was supported by a Senior Post-doctoral 527 Fellowship at the University of Pretoria.

528

529

530 DECLARATION OF INTESTEST

531 The authors declare no conflict of interest. 
533

534 Table 1: Output of the cox proportional hazards model to investigate the influence of three 535 social factors on a male's group tenure length (Model 1). Social factors were 1) the highest 536 rank position a male achieved, 2) the highest grooming EC score a male achieved and 3) the 537 highest proximity degree score a male achieved. $\mathrm{N}=44$ migratory events plus 32 censored 538 males. Whole model: $\log$-likelihood $=-149.71: \mathrm{X}_{3}{ }_{3}=60.30, \mathrm{P}<0.001 ; \mathrm{R}^{2}{ }_{\text {adj }}=0.570 . \beta$ is the 539 hazard rate coefficient where a positive value indicates an increased risk of a male migrating.

540

541

\begin{tabular}{|l|l|l|l|c|}
\hline Factor & $\boldsymbol{\beta} \pm \mathbf{s e}$ & $\begin{array}{l}\text { Hazard } \\
\text { ratio }\end{array}$ & $\mathbf{z}$ value & $\operatorname{Pr}(>|\mathbf{z}|)$ \\
\hline $\begin{array}{l}\text { Highest rank a } \\
\text { male achieved }\end{array}$ & $-1.124 \pm 0.293$ & 0.325 & -3.830 & $<0.001$ \\
\hline $\begin{array}{l}\text { Highest grooming } \\
\text { EC a male } \\
\text { achieved }\end{array}$ & $-0.469 \pm 0.272$ & 0.625 & -1.730 & 0.084 \\
\hline $\begin{array}{l}\text { Highest proximity } \\
\text { degree a male } \\
\text { achieved }\end{array}$ & $-0.827 \pm 0.250$ & 0.437 & -3.300 & $<0.001$ \\
\hline
\end{tabular}


544 Table 2: Output of the cox proportional hazards model (Model 2) to investigate the influence

545 of social factors on a male's group tenure length subsequent to achieving his highest rank.

546 Social factors were 1) the highest rank position a male achieved, 2) the highest grooming EC

547 score a male achieved, 3) the highest proximity degree score a male achieved and 4) a male's

548 group residency length before achieving their highest rank. $\mathrm{N}=44$ migratory events plus 19

549 censored males. Whole model: $\log$-likelihood $=-140.23: \mathrm{X}_{4}{ }_{4}=24.58, \mathrm{P}<0.001 ; \mathrm{R}^{2}{ }_{\text {adj }}=0.341$.

$550 \beta$ is the hazard rate coefficient where a positive value indicates an increased probability of

551 longer tenure length.

552

553

554

\begin{tabular}{|l|c|c|c|c|}
\hline Factor & $\mathbf{B} \pm \mathbf{s e}$ & $\begin{array}{l}\text { Hazard } \\
\text { ratio }\end{array}$ & $\mathbf{z}$ value & $\operatorname{Pr}(>|\mathbf{z}|)$ \\
\hline Highest rank achieved & $-0.994 \pm 0.410$ & 0.370 & -2.450 & 0.014 \\
\hline $\begin{array}{l}\text { Highest grooming EC } \\
\text { achieved }\end{array}$ & $-0.283 \pm 0.400$ & 0.753 & -0.710 & 0.480 \\
\hline $\begin{array}{l}\text { Highest proximity } \\
\text { degree achieved }\end{array}$ & $-1.184 \pm 0.459$ & 0.306 & -2.580 & 0.010 \\
\hline $\begin{array}{l}\text { Group residency length } \\
\text { prior to highest rank }\end{array}$ & $0.574 \pm 0.389$ & 1.775 & 1.480 & 0.140 \\
\hline
\end{tabular}

555

556 
557 Table 3: Output of the cox proportional hazards model to investigate the influence of several

558 social factors on a male's decision to emigrate or not $(\mathrm{N}=37$ migratory events plus 19

559 censored males). Social factors were the number of males and females, male standardised

560 rank, male power trajectory, two SN measures (grooming EC and proximity degree), the

561 proportion of female with a dependant infant, and male mating success. Whole model: log-

562 likelihood $=-97.617: \mathrm{X}_{8}^{2}=15.75, \mathrm{P}=0.046, \mathrm{R}_{\text {adj }}^{2}=0.07 . \beta$ is the hazard rate coefficient

563 where a positive value indicates an increased risk of a male migrating.

564

565

\begin{tabular}{|l|l|c|c|c|}
\hline Factor & $\boldsymbol{\beta} \pm \mathbf{s e}$ & $\begin{array}{l}\text { Hazard } \\
\text { ratio }\end{array}$ & $\mathbf{z}$ value & $\operatorname{Pr}(>|\mathbf{z}|)$ \\
\hline Difference in proximity degree & $-0.249 \pm 0.182$ & 0.780 & -1.370 & 0.170 \\
\hline Difference in grooming EC & $-0.449 \pm 0.173$ & 0.638 & -2.590 & 0.001 \\
\hline Standardized rank & $-0.034 \pm 0.197$ & 0.966 & -0.170 & 0.860 \\
\hline Power trajectory & $-0.153 \pm 0.156$ & 0.858 & -0.980 & 0.330 \\
\hline Mating success & $-0.227 \pm 0.214$ & 0.797 & -1.060 & 0.290 \\
\hline Male number & $0.299 \pm 0.233$ & 1.349 & 1.280 & 0.200 \\
\hline Female number & $-0.536 \pm 0.237$ & 0.585 & -2.260 & 0.024 \\
\hline $\begin{array}{l}\text { Proportion of females with } \\
\text { dependent infants }\end{array}$ & $-0.212 \pm 0.198$ & 0.809 & -1.070 & 0.280 \\
\hline
\end{tabular}


575 Figure 1: Showing kernel density estimates of the number of male migration events (yellow), 576 the number of copulations (dark blue) and the number of conceptions (sky blue) per week of

577 the year (1-52 weeks). Also shown are the mean \pm SD fAM levels of five males for the

578 months of January to May in order to show the timing of peak androgen production.

579

580 Figure 2: The log-survivorship curve of non-natal males as a function of residency length (red

581 circles). The best-fit segmented regression slopes are fitted as a solid black line $\left(\mathrm{R}^{2}\right.$ adj. $=$

582 0.99), and the two identified break points are indicated by dashed lines. The modal age at first

583 birth by females is indicated by the dotted line.

584

585 Figure 3: The relationship between rank and male residency length (model 2). The y-axis

586 indicates survival probability, while the x-axis indicates the number of days in residence. For

587 illustrative purposes the data are split into two groups: males of high rank (solid black line)

588 versus males of low rank (dashed red line).

589

590 Figure 4: The influence of increasing or decreasing social integration (grooming EC) on the

591 decision to leave a group (model 3). The y-axis indicates the probability of survival, while the

592 survival time in three-month time blocks from entry into the group (time 0 ) is indicated on

593 the x-axis. For illustrative purposes the data are split into two groups: increase in grooming

594 EC (solid black line) and decrease in grooming EC (dashed red line).

595 


\section{REFERENCES}

Agostinelli, C., \& Lund, U. (2011). circular: Circular statistics. URL http://cran. r-project. org/src/contrib/Descriptions/CircStats. html,

Albers, P. C. H., \& de Vries, H. (2001). Elo-rating as a tool in the sequential estimation of dominance strengths. Animal Behaviour, 61, 489-495.

Alberts, S. C. (1999). Paternal kin discrimination in wild baboons. Proceedings of the Royal Society of London B: Biological Sciences, 266, 1501-1506.

Altmann, J. (1974). Observational sampling of behavior: sampling methods. Behaviour, 49, 227-266.

Barton, K., \& Barton, M. K. (2015). Package 'MuMIn'. ftp://155.232.191.229/cran/web/packages/MuMIn/,

Bercovitch, F. B. (1988). Coalitions, cooperation and reproductive tactics among adult male baboons. Animal Behaviour, 36, 1198-1209.

Bramblett, C. A., Pejaver, L. D., \& Drickman, D. J. (1975). Reproduction in captive vervet and Sykes' monkeys. Journal of Mammalogy, 56, 940-946.

Castles, M., Heinsohn, R., Marshall, H. H., Lee, A. E. G., Cowlishaw, G., \& Carter, A. J. (2014). Social networks created with different techniques are not comparable. Animal Behaviour, 96, 59-67.

Cheney, D. L., \& Seyfarth, R. M. (1983). Nonrandom dispersal in free-ranging vervet monkeys: social and genetic consequences. The American Naturalist, 122, 392-412.

Cheney, D. L., \& Seyfarth, R. M. (1992). How Monkeys See the World: Inside the Mind Of Another Species. Chicago, Ill.: University of Chicago Press. 
Clarke, P. M. R., Henzi, S. P., Barrett, L., \& Rendall, D. (2008). On the road again: competitive effects and condition-dependent dispersal in male baboons. Animal Behaviour, 76, 55-63.

Colquhoun, D. (2014). An investigation of the false discovery rate and the misinterpretation of p-values. Royal Society Open Science, 1, 140216.

Curran, J., \& Bolstad, W. (2017). Bolstad: Bolstad functions. R Package Version 0.2-34. https://cran.r-project.org/web/packages/Bolstad/index.html,

Dubuc, C., Muniz, L., Heistermann, M., Engelhardt, A., \& Widdig, A. (2011). Testing the priority-of-access model in a seasonally breeding primate species. Behavioral Ecology and Sociobiology, 65, 1615-1627.

Fox, J., \& Weisberg, S. (2011). An R Companion to Applied Regression (Second ed.). Thousand Oaks CA: Sage. Retrieved from http://socserv.socsci.mcmaster.ca/jfox/Books/Companion

Freeman, N. J., Young, C., Barrett, L., \& Henzi, S. P. (2016). Coalition formation by male vervet monkeys (Chlorocebus pygerythrus) in South Africa. Ethology, 122, 45-52.

Ganswindt, A., Heistermann, M., Borragan, S., \& Hodges, J. K. (2002). Assessment of testicular endocrine function in captive African elephants by measurement of urinary and fecal androgens. Zoo Biology, 21, 27-36.

Greenwood, P. J. (1980). Mating systems, philopatry and dispersal in birds and mammals. Animal Behaviour, 28, 1140-1162.

Henzi, S. P., Clarke, P. M. R., van Schaik, C. P., Pradhan, G. R., \& Barrett, L. (2010). Infanticide and reproductive restraint in a polygynous social mammal. Proceedings of the National Academy of Sciences, 107, 2130-2135. 
Henzi, S. P., Forshaw, N., Boner, R., Barrett, L., \& Lusseau, D. (2013). Scalar social dynamics in female vervet monkey cohorts. Philosophical Transactions of the Royal Society B, 368, 20120351.

Henzi, S. P., \& Lucas, J. W. (1980). Observations on the inter-troop movement of adult vervet monkeys (Cercopithecus aethiops). Folia Primatologica, 33, 220-235.

Hyndman, R. J., \& Khandakar, Y. (2008). Automatic time series forecasting: the forecast package for R. Journal of Statistical Software, 26, 1-22.

JMP, Version 13 (2013). SAS Institute Inc., Cary, NC.

Josephs, N., Bonnell, T., Dostie, M., Barrett, L., \& Henzi, S. P. (2016). Working the crowd: sociable vervets benefit by reducing exposure to risk. Behavioral Ecology, 27, 988-994.

McFarland, R., Fuller, A., Hetem, R. S., Mitchell, D., Maloney, S. K., Henzi, S. P., \& Barrett, L. (2015). Social integration confers thermal benefits in a gregarious primate. Journal of Animal Ecology, 84, 871-878.

Mills, M. (2011). Introducing survival and event history analysis. London: Sage.

Minkner, M. M. I., Young, C., Amici, F., McFarland, R., Barrett, L., Grobler, J. P., Henzi, S. P., \& Widdig, A. (2018). Assessment of male reproductive skew via highly polymorphic STR markers in wild vervet monkeys, Chlorocebus pygerythrus. Journal of Heredity, 109, 780-790.

Muniz, L., Perry, S., Manson, J. H., Gilkenson, H., Gros-Louis, J., \& Vigilant, L. (2006). Father--daughter inbreeding avoidance in a wild primate population. Current Biology, 16, R156-R157.

Nakagawa, S., \& Schielzeth, H. (2012). A general and simple method for obtaining Rcol2 from generalized linear mixed-effects models. Methods in Ecology and Evolution, 4, 133-142. 
Neumann, C., Duboscq, J., Dubuc, C., Ginting, A., Irwan, A. M., Agil, M., Widdig, A., \& Engelhardt, A. (2011). Assessing dominance hierarchies: validation and advantages of progressive evaluation with Elo-rating. Animal Behaviour, 82, 911-921.

Noë, R., \& Sluijter, A. A. (1995). Which adult male savanna baboons form coalitions? International Journal of Primatology, 16, 77-105.

Palme, R., \& Möstl, E. (1993). Biotin-streptavidin enzyme immunoassay for the determination of oestrogens and androgens in boar faeces. In S. Görög (Ed.), Advances of steroid analysis '93 (pp. 111-117). Budapest: Akademiai Kiado.

Pan, Y., \& Jackson, R. T. (2008). Ethnic difference in the relationship between acute inflammation and serum ferritin in US adult males. Epidemiology and Infection, 136, $421-431$.

Pasternak, G. M., Brown, L. R., Kienzle, S., Fuller, A., Barrett, L., \& Henzi, S. P. (2013). Population ecology of vervet monkeys in a high latitude, semi-arid riparian woodland. Koedoe, 55, Art. \#1078.

Pusey, A. E., \& Packer, C. (1987). The evolution of sex-biased dispersal in lions. Behaviour, $101,275-310$.

R-Core-Team. (2016). R: A language and environment for statistical computing. Vienna: R Foundation for Statistical Computing.

Schmid, V. S., \& de Vries, H. (2013). Finding a dominance order most consistent with a linear hierarchy: an improved algorithm for the I\&SI method. Animal Behaviour, 86, 1097-1105.

Schülke, O., \& Ostner, J. (2012). Ecological and social influences on sociality. In J. C. Mitani, J. Call, P. M. Kappeler, R. A. Palombit, \& J. B. Silk(pp. 195-219). Chicago: University of Chicago Press. 
Therneau, T. M., \& Grambsch, P. M. (2013). Modeling survival data: extending the Cox model. Berlin: Springer.

Therneau, T. M., \& Therneau, M. T. M. (2015). coxme: Mixed effects Cox models. Version 2. UR L http://CRAN. R-project. org/package= coxme. $R$ package version,

Therneau, T. M. (2014). A Package for Survival Analysis in S. 2014. R package version 2.37-7. http://CRAN.R-project.org package=survival,

van Noordwijk, M. A., \& van Schaik, C. P. (2004). Sexual selection and the careers of primate males: paternity concentration, dominance-acquisition tactics and transfer decisions. In P. M. Kappeler \& C. P. van Schaik (Eds.), Sexual Selection in Primates: New and Comparative Perspectives (pp. 208-229). Cambridge: Cambridge University Press.

Vito, M. R. M. (2008). segmented: An R Package to Fit Regression Models with BrokenLine Relationships. $R$ News, 8, 20-25.

Westermarck, E. (1891). Human Marriage in The History of Mankind. London: MacMillan. Young, C., Hähndel, S., Majolo, B., Schülke, O., \& Ostner, J. (2013). Male coalitions and female behaviour affect male mating success independent of dominance rank and female receptive synchrony in wild Barbary macaques. Behavioral Ecology and Sociobiology, 67, 1665-1677.

Young, C., McFarland, R., Barrett, L., \& Henzi, S. P. (2017a). Formidable females and the power trajectories of socially integrated male vervet monkeys. Animal Behaviour, 125, $61-67$.

Young, C., Ganswindt, A., McFarland, R., de Villiers, C., van Heerden, J., Ganswindt, S., Barrett, L., \& Henzi, S. P. (2017b). Faecal glucocorticoid metabolite monitoring as a measure of physiological stress in captive and wild vervet monkeys. General and Comparative Endocrinology, 253, 53-59. 


\section{Male residency and dispersal triggers in a seasonal breeder with influential females}

Christopher Young ${ }^{\mathrm{a}, \mathrm{b}, \mathrm{c}}$, Richard McFarland ${ }^{\mathrm{b}, \mathrm{d}, \mathrm{e}}$, Andre Ganswindt ${ }^{\mathrm{a}}$, Mirjam M.I. Minkner b,f,g , Louise Barrett ${ }^{\mathrm{b}, \mathrm{c}}$, and S. Peter Henzi ${ }^{\mathrm{b}, \mathrm{c}}$

\section{Highlights}

- Eight years of male vervet monkey social data across three groups

- Migration is seasonal, peaking with androgen levels but before peak conception

- Residency length positively associated to dominance rank and social measures

- Probability to emigrate negatively associated to female number/grooming effort

- Emigration linked to male rank and mediated by female network integration 
Figure 1

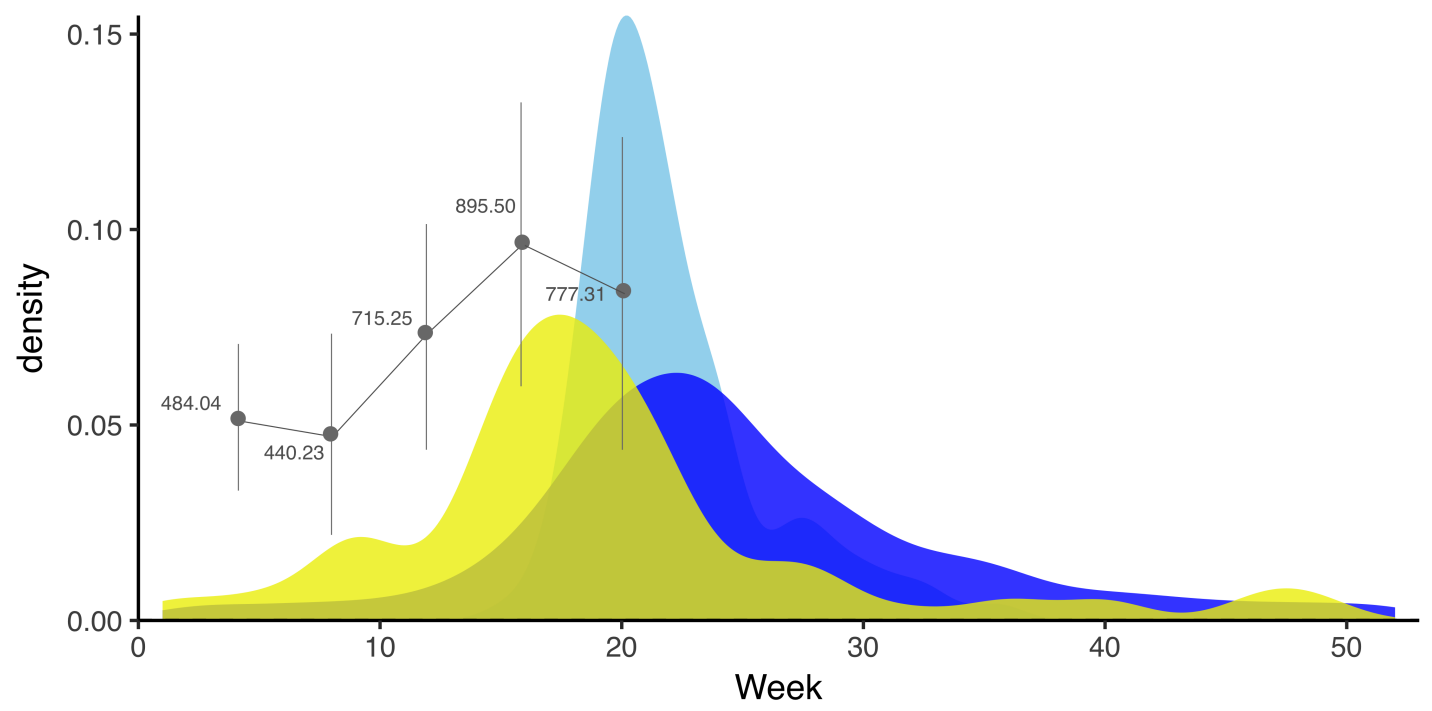




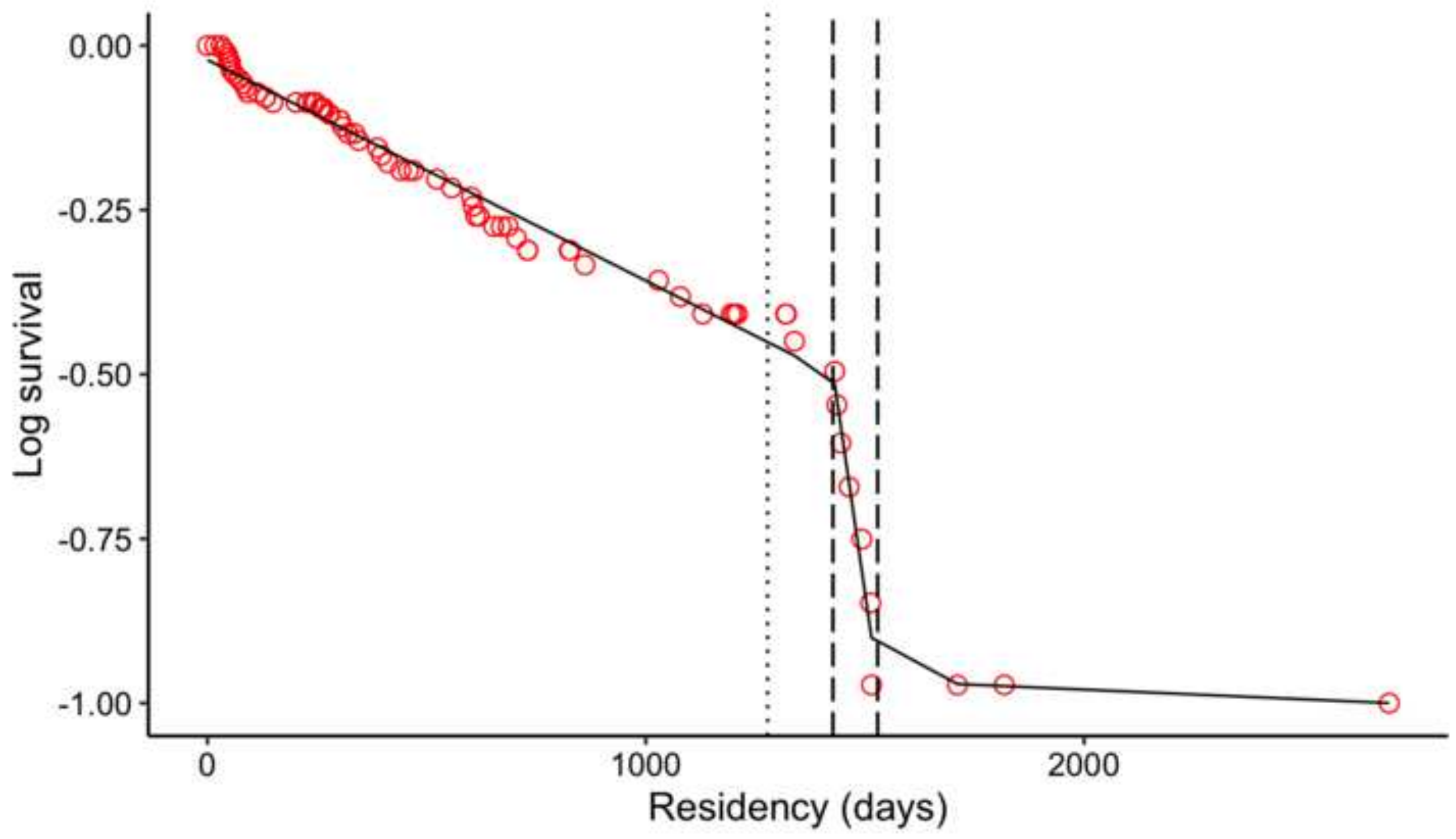


Click here to download high resolution image

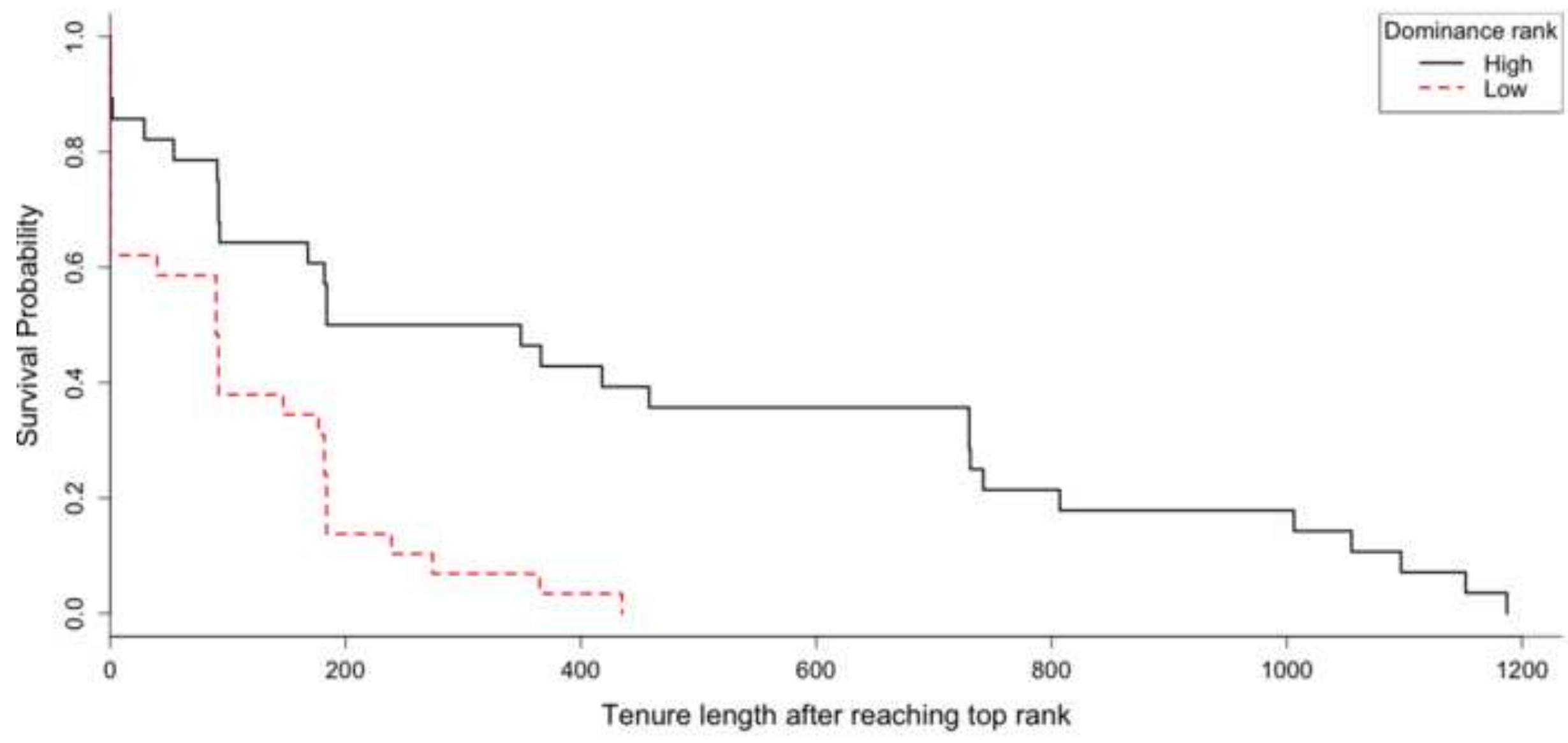


Click here to download high resolution image

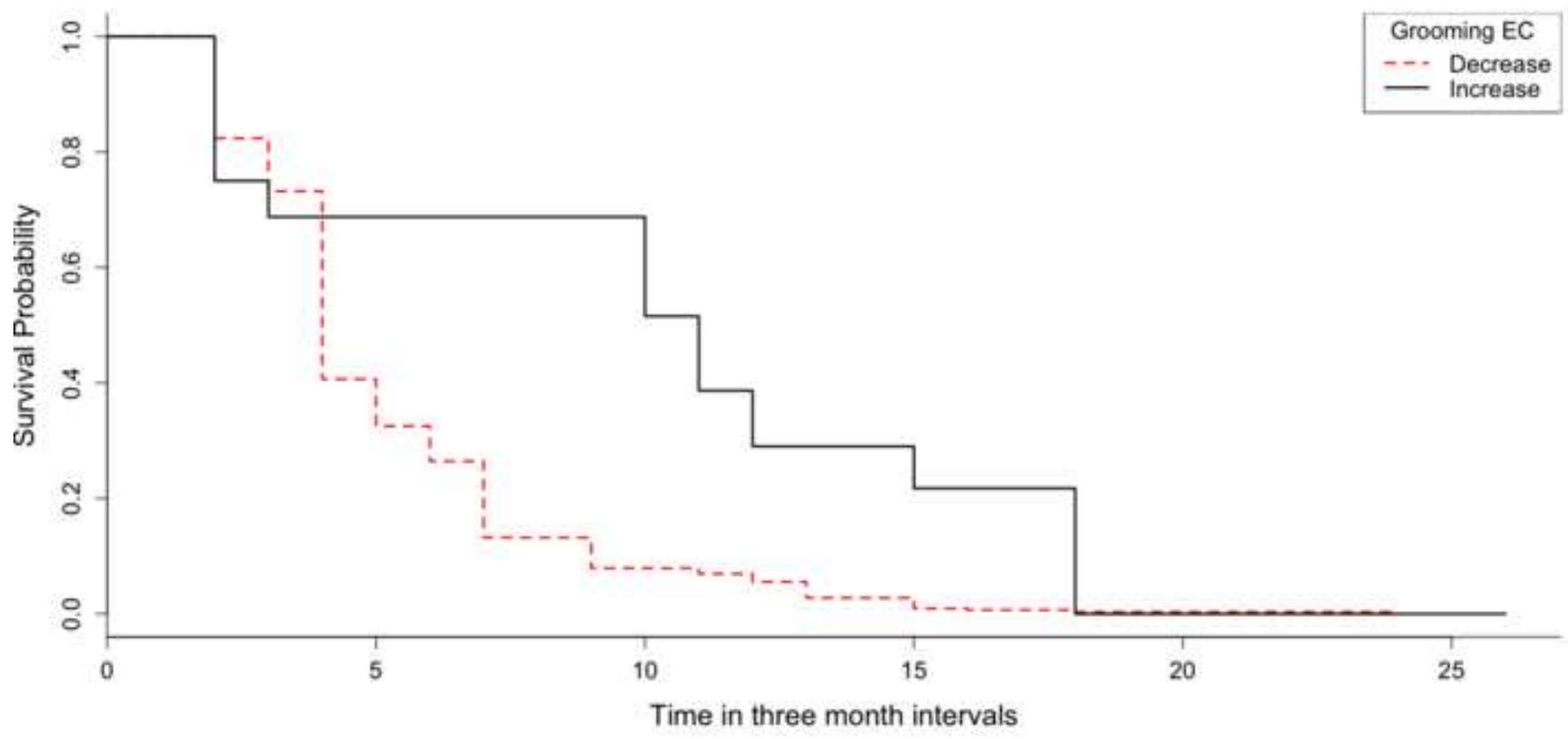




\section{Male residency and dispersal triggers in a seasonal breeder with influential females}

Christopher Young ${ }^{\mathrm{a}, \mathrm{b}, \mathrm{c}}$, Richard McFarland ${ }^{\mathrm{b}, \mathrm{d}, \mathrm{e}}$, Andre Ganswindt ${ }^{\mathrm{a}}$, Mirjam M.I. Minkner b,f,g , Louise Barrett ${ }^{\mathrm{b}, \mathrm{c}}$, and S. Peter Henzi ${ }^{\mathrm{b}, \mathrm{c}}$

Ethical note: All protocols were non-invasive and adhered to the laws and guidelines of South Africa and Canada. Procedures were approved by the University of Lethbridge Animal Welfare Committee (Protocols 0702 and 1505). This study also adheres to the ASAB/ABS Guidelines for the Use of Animals in Research. 